The observation is straightforward. The approximate altitude is set on the sextant according to ship's time for each star in turn and the star observed on the known bearing. As each altitude is recorded with the chronometer time, the azimuth corresponding to this altitude can be taken from the tables so as to save time later when plotting.

It might seem that a selection of six stars, particularly in cloudy weather, is not enough. However, in cloudy weather the best procedure is to set the approximate altitude on the sextant in the hope of snapping the star through a break in the clouds. In clear weather six stars well selected for cut and magnitude should be all that the navigator normally requires.

When great accuracy is required, for example when only two stars have been obtained, with perhaps a poor angle of cut, or for specialized requirements such as in cable ships when the time factor is of less importance, the sights will best be worked up by the full-length formula. In this case the tables will still be useful for providing the azimuth by inspection and for use in planning the observation which should enable a better horizon and thus a more accurate altitude to be obtained. When the time factor is relatively more important than a possible loss of accuracy, the tables enable six stars to be worked rapidly and the mean position given by the intersection of the position lines will certainly yield a valuable and reliable position.

One of the great advantages of A.P. 3270 is that all the stars are used with a common argument, L.H.A. Aries, with no interpolation for declination. On the other hand the relatively large distances between the observed and assumed positions on some occasions constitutes a drawback, making the plotting a little cumbersome and open to inaccuracy. The most efficient use of a series of altitudes will be arrived at if the observer's methods are kept elastic and the most profitable combination used, each sight being considered on its own merits. For example, on some occasions it may be better to work three stars to a high accuracy rather than six using A.P. 3270 . In this case the accuracy of the final positions would probably be similar and their time of working the same. On the other hand where all observations are sub-standard it will usually be better to work six stars with A.P. 3270 than three stars more accurately. When doubt of the vessel's safety requires an urgent indication of position, two stars worked with A.P. 3270 or even one position line should be sufficient to remove uncertainty. Then a more accurate position can be worked for the necessary adjustment of course.

\title{
Plotting as an Aid to the Avoidance of Collisions at Sea
}

\author{
from Captain G. C. Forrest
}

\section{(S.S. Arcadia)}

I THIN that the impression which would be left by the Institute Working Party's Report (Journal, Vol. VII, p. 219) in the mind of any of the learned gentlemen of the Admiralty courts would be that a ship which did not keep a radar plot should be considered guilty of 'neglect of any precaution' under Article 29 of 
the Collision Regulations, and this impression could lead to a miscarriage of justice.

There are three particular points I disagree with in the report:

(I) The use of the word 'essential' where I would have preferred to write 'plotting may be advantageous in some cases, when it is desirable to continue it' as being closer to the practical truth.

(2) The inference that the only alternative to plotting is 'mere observation of the progress of the other ship's echo across the face of the PPI', whereas in practice inspection of the PPI can give the trained observer nearly all the information that can be obtained from a plot; it will always tell him (before the closequarter situation develops) whether risk of collision exists-because in that case the bearing does not change while the range decreases; sometimes there is information on the PPI which does not appear on the plot; for example, there are large echoes and small echoes, some have comet-like tails while others have not, and on the close-range large scale the echo of the other ship is frequently long enough to give a very good idea of her aspect. All these things have meaning and value to the eye of experience.

(3) Examples which use speeds of I 8 knots or more are lacking in reality. If we are to assume, as we must, that these cases take place in uniformly dense fog, so thick that both ships are relying entirely on their radar to avoid collision, then no responsible person would proceed at so high a speed in the known near presence of another ship or ships.

To conclude: my experience in command of radar-fitted ships for the past seven years shows that where two ships have approached to within four miles of each other in fog, on courses which involve some risk of collision, if the master of one of them assumes that the other will maintain his course and/or speed, he will be wrong three times out of four. Therefore plotting does not help much unless the close-quarter situation can be avoided entirely, when it should allow the manœuvre to be performed economically and neatly; but that is rather a broad interpretation of 'avoidance of collision'.

Plotting has enough value to make it desirable that where the necessary personnel are available a plot should be kept, providing that the dangers inherent in attempting to forecast the future from past history are never forgotten. I would give precedence to an unbroken watch on the PPI, if it were not practical to do both, in order to ensure that a small intermittent echo, as. from a fishing vessel, in the trough of the swell or behind the foremast, did not get missed.

Captain Wylie wrote long ago that the main value of radar would probably lie in avoiding the close-quarter situation altogether, and there is now no doubt that this is so; it also has the secondary value of saving time in the unavoidable close-quarter situation; but the fundamental cause of collision is now as it always has been-simply failure to stop.

\section{Captain F. J. Wylie, the Chairman of the Working Party, writes:}

I have great respect for Captain Forrest's views. On his bridge, we have discussed plotting and plotters. It appears to me that his letter is saying that plotting is all very well, but it does not solve all problems. I entirely agree with him, but I would like very briefly to take up his three points:

(r) The report very cautiously says 'plotting may be essential rather than merely advisable'. I think Captain Forrest is unfair in giving this sentence a 
general application when, in its context, it is merely a warning that there may be particular circumstances which only plotting will unravel with certainty.

(2) Captain Forrest and I are obviously agreed on the desirability of avoiding the close-quarter situation. No one will suggest that the plot is necessary to discover whether the bearing is moving; on the other hand, few will be able to tell from changes of bearing and range alone, e.g. so many degrees and so many miles in 5 minutes, whether a close-quarter situation is likely to develop; hence the remark quoted.

I entirely agree that the eye of experience can read much from the PPI, but the most experienced can read little from the nature of a ship echo at 8-10 miles, and it is that kind of range with which the report was dealing.

(3) With this unfortunately I cannot agree. There are many fast ships which decrease speed but little in fog. In any case, I do not think the principles or the examples depend upon 'pea soup' conditions.

1 have no comment other than agreement on Captain Forrest's conclusion, except to say that I think he overestimates the amount of labour which would be involved in plotting, when experience has made it second nature, and underestimates the value of establishing a common procedure for all closing echoes, including, when practicable, a plot which will distinguish the close-quarter situation from others with the greatest speed and certainty and can be followed up or dropped as the depicted situation demands.

\section{Radar and Collision at Sea}

$$
\text { from Captain C. F. Halliday }
$$

$$
\text { (S.S. Corfu) }
$$

Captain Wylie's note 'Radar and the Compass Bearing' (Journal, Vol. VII, p. 200) voices the objection to the ship's-head-up display because it gives bearings relative to the fore-and-aft line instead of to the axis of the compass card. This objection will not appear to be a very real one to anybody accustomed to using a dumb-card pelorus: a glance at the compass, or a word to the man at the wheel, will give the correction to be applied to the bearing in order to make it relative to the course by compass. If the ship is a degree right of her course we add a degree, if two degrees left we subtract two, and so on, before using the bearing. If plotting, the plot is a course-up plot, not a ship's-head-up plot. It is, in fact, a compass-datum plot with a more convenient orientation than the north-up which is so strongly advocated. It would appear to be mere hairsplitting to regard the corrected bearings as not being compass bearings within the meaning of the Steering and Sailing Rules since the important thing is whether or not the bearing is changing appreciably and not the number of degrees it contains. However, this objection, and that of the angular displacement of the plotted tracks of targets when course is altered, can both be completely negatived by using the course-up, gyro-stabilized display; the heading marker is set to zero when the ship is on her course and the gyro allowed to take care of yaw. 